BULLETIN Bulletin hispanique

HISPANIQUE Université Michel de Montaigne Bordeaux

$113-2$ | 2011

Varia

\title{
Metamorfosis e identidad en la escritura autobiográfica de María Casares
}

\section{Ángeles Ezama Gil}

\section{OpenEdition}

\section{Journals}

\section{Edición electrónica}

URL: http://journals.openedition.org/bulletinhispanique/1428

DOI: 10.4000/bulletinhispanique.1428

ISSN: 1775-3821

\section{Editor}

Presses universitaires de Bordeaux

\section{Edición impresa}

Fecha de publicación: 1 diciembre 2011

Paginación: 633-662

ISBN: 978-2-86781-793-9

ISSN: 0007-4640

\section{Referencia electrónica}

Ángeles Ezama Gil, « Metamorfosis e identidad en la escritura autobiográfica de María Casares »,

Bulletin hispanique [En línea], 113-2 | 2011, Publicado el 01 diciembre 2014, consultado el 21 abril 2019.

URL : http://journals.openedition.org/bulletinhispanique/1428; DOI : 10.4000/bulletinhispanique.1428 


\title{
Metamorfosis e identidad en la escritura autobiográfica de María Casares
}

\author{
Ángeles Ezama GiL \\ Universidad de Zaragoza - España
}

L'actrice espagnole Maria Casarès a publié un seul livre, Résidente privilégiée (1980), une autobiographie écrite en français, qui est aussi une magnifique æeuvre littéraire; dans ce récit de vie, les métamorphoses constituent pour l'auteur le moyen de reconstruire une identité perdue à la suite de la guerre et de l'exil en France, ainsi que d'autres amputations subies tout au long de sa vie, identité quielle finit par conquérir.

La actriz española María Casares publicó un único libro, Résidente privilégiée (1980), una autobiografia escrita en lengua francesa que es una magnifica obra literaria; en este relato las metamorfosis constituyen el medio de que la autora se vale para buscar una identidad perdida con la guerra y el exilio y con otras amputaciones experimentadas a lo largo de su vida, identidad que finalmente consigue alcanzar.

Spanish actress Maria Casares wrote only one book in her life, Résidente privilégiée (1980), an autobiography written in French, a wonderful literary text; in that story, the metamorphosis or avatars are the means the author uses to reconstruct her identity -lost following the war and exile to France- and the successive losses she experienced throughout her life; the new identity which, in the end, she manages to conquer.

Mots-clés : Maria Casarès - Résidente privilégiée - Autobiographie - Métamorphose - Identité.

Bulletin Hispanique, Tome 113, nº 2 - décembre 2011 - p. 633 à 662. 
Et si ce livre ne peut ni ne veut répondre à ce qui serait considéré comme un livre de mémoires, car je n'en ai aucune, du moins il se doit de rester en accord fidèle à ce que me dicte "ma mémoire" puisque c'est justement pour aller à sa recherche que j'ai décidé de l'écrire. (Casares, 1980: 161)

Yo no he querido escribir mis memorias. El libro todo entero responde a una búsqueda de lo que sería mi fidelidad. (Casares en Jacinto Soriano, 1988: 60)

\section{EL LIBRO... Y SU SEGUNDA PARTE (NUNCA ESCRITA)}

El 7 de noviembre de 1977 María Casares firma un contrato de edición con la Librería Arthème Fayard, representada por Alex Grall, por el cual se compromete a entregar antes del 30 septiembre de 1979 un libro de memorias cuyo título provisional es el de Carte de séjour, résidente privilégiée; Bernard Clesca era el editor de Fayard, que se dirigió a ella antes de su marcha a España para interesarla por el proyecto; no obstante, María sólo aceptó el desafío tras su vuelta, con la condición de que ella fuera la única en proceder a la redacción del libro, ya que le parecía imposible confiarse a un micro y que personas extrañas retranscribiesen sus palabras (Figuero y Carbonel, 2005: 256-257). El proyecto, terminado el 30 de septiembre de 1979, fue posible tras un costoso periodo de gestación; en entrevista concedida a la actriz Tina Sainz María le confía: "Je meenfermai pendant neuf mois, ce fut comme une gestation.» (Ibid:: 269) El libro, con el título de Résidente privilégiée se editó finalmente en Paris, en la librería de Arthème Fayard, en 1980, y fue objeto de una amplia acogida en la prensa contemporánea, en particular la francesa (Ibid.: 270-273); en 1981 se publicó la traducción española, realizada por Fabián García-Prieto Buendía y Enrique Sordo, con el título de Residente privilegiada (Madrid, Argos Vergara), sobre la que diría María en entrevista con Carlos Fernández Santander que «fue mayormente correcta» (Casares, julio de 1991: 308); por último, en este mismo año de 2009 acaba de aparecer la traducción en gallego con el título de Residente privilexiada, realizada por Ana Belén Martínez Delgado para la editorial Trifolium.

La autoría del libro corresponde indudablemente a María Casares, pero en ella una parte no pequeña del discurso pertenece a su padre Santiago Casares, algunas de cuyas cartas y agendas ayudan a reconstruir el periodo final de la vida del político gallego: 
Je me demande quand et comment je trouvais le temps d'entretenir avec mon père ce "duel» épistolaire dont il parle régulièrement dans les lettres que j'ai gardées de lui à l'époque et que je fus toujours incapable de relire depuis sa mort jusqu'au jour où j'entrepris, avec mon voyage en Espagne, l'aventureux trajet qui me mena à écrire ce livre et qui, pour commencer, m’obligea à forcer les tiroirs secrets restés jusqu'ici tabou, à la recherche de clés qui m’aident à ouvrir des portes jusque-là condamnées. (Casares, 1980: 316)

En este relato autobiográfico la palabra tiene un valor primordial, suscitando en la autora y protagonista una emoción irreprimible:

C'est vrai; un mot exactement employé -inventé, trouvé ou retrouvépeut m'émouvoir aux larmes ou me faire rire de plaisir. C'est pourquoi j'ai toujours aimé au théâtre parler le langage des poètes et c'est pourquoi, placée devant un texte riche de fruits, une de mes plus dangereuses tentations sur une scène est celle qui me porte trop souvent à m'attarder sur une expression savoureuse ou à trop mettre en évidence des mots dont le sens, l'esprit, et la musique, vibrent pour moi en parfait accord. Et c'est aussi pourquoi, malgré une latente envie d'écrire qui est venue toujours tracasser mes rares moments de loisir, écartelée comme je le suis entre deux langues qui me narguent en se camouflant l'une l'autre, châtrée d'un vrai langage, j'ai préféré me rendre à l'authenticité - par l'interprétationou l'interpénétration - des trouvailles parfois divines créées par d'autres. (Ibid.: 144-145)

Esta devoción por la palabra está ya en la infancia, en las nociones inculcadas por su padre o en las historias de carácter maravilloso contadas por su madre y por otros miembros de la familia; contrastando con ella, el silencio, del que aprende con el padre (Ibid.: 39) y durante la guerra (Ibid.: 112). Más adelante sobreviene la dificultad de evitar la lengua propia para asimilar un idioma ajeno como el francés y así poder familiarizarse con los textos en el imprescindible aprendizaje teatral (Ibid.: 138, 144), ya que el actor es «celui qui est fait pour agir par le geste et la parole» (Ibid.: 345).

De modo que el discurso de la autobiografía de María Casares se nutre de la narración oral, de los textos literarios y de las cartas y agendas del padre, pero también de la voz objetiva del diccionario, al que recurre la autora para buscar el sentido de la existencia cuando la desorientación vital la conduce incluso al olvido de su nombre (libro III, I). En el diccionario trata de encontrar significado a las palabras "Destin -Terre-Enterrement -Vivre-Innocence-Renaître-Liberté», pero también "aeuf», "père», "souvenir» (Ibid.: 341), y sobre todo «trou» (Ibid.: 343, 394). Esta palabra clave funciona 
de modo polisémico, designando tanto una "ouverture, cavité», como la "cavité dans laquelle loge un animal» y la "solution de continuité» ("rupture, vide, lacune, défaut», Ibid.: 419), pero además, en francés el término también significa la "fosse creusée dans la terre pour y enterrer les morts», y sugiere además "vide total, absence de matière», significados que cobran sentido todos ellos en esa quiebra interior que supone en el personaje la muerte sucesiva del padre y del amante.

La palabra establece un vínculo indisoluble entre escritura y teatro; ambos surgen del mismo impulso:

Je me demande quelle est la raison vitale qui m’a poussée à écrire ce livre. Si toutefois il y en a une. Et si encore une fois ce n'est pas la même qui m'a projetée dans le théâtre, la construction sans cesse recommencée d'un foyer, d'une famille, de racines réinventées, d'amitiés et d'amours renouvelées et tenues à la force du poignet. (Casares, 1980: 105)

Los dos forman parte de la serie de actividades que el ser humano realiza a lo largo del camino que le conduce a la muerte, permiten exorcizar las vivencias dolorosas (Ibid.: 109, 115) y sólo cobran sentido en el proceso de búsqueda:

J'aimerais bien que la mort se présentât à moi comme une sente et avoir la pleine possibilité de la voyager en toute conscience.

Quant à l'espace parcouru, quelle importance? Jouer sur une scène, attendre l'homme qu'on aime, construire une maison, écrire, plonger dans l'océan, rôtir au soleil, humer l'odeur fermentée de l'automme charentais, passer avec soin l'aspirateur ou cirer un mueble avec rage ou avec tendresse, quelle différence? (Ibid.: 109)

De ahí que María tuviera en en mente escribir un segundo libro sobre el teatro, complemento de este primero, que no llegó a hacerse realidad:

Aujourd'hui je sais que, pour mieux chercher qui je suis, il faudrait à ce livre un second volet; celui où, à travers le théâtre, les camarades de travail, les personnages de fiction... je chercherais encore quelle peut être cette patrie mouvante où je me suis enracinée, et qui peut bien être cette figure qui est la mienne -la même et toujours métamorphosée plus rêvée -à ce quill mien apparaît-que toutes celles que j'ai incarnées. (Ibid.: 419-420)

Pero esta "segunda hoja» está de alguna manera presente en el libro que nos ocupa, dada la irrefrenable vocación teatral de la autora que resulta inseparable de su devenir vital; por ello la metamorfosis es nuclear en la 
definición de la identidad de la autora, tanto en la vida como en el teatro. En la entrevista que hizo a la actriz Joaquín Soler Serrano para el programa de televisión «A fondo» (1981a) añade:

Lo que no dije en el libro, lo que no hablé, es decir, toda la parte de identidad que se podría encontrar a través de lo que se ha hecho en el teatro. Porque a veces me pregunto: Si no hubiera hecho todos los monstruos que he hecho en el teatro, ¿qué es lo que hubiera sido como persona?

\section{LA CRÍTICA}

Muy poco es lo que se ha escrito hasta el momento sobre este magnífico texto literario, y en ello probablemente tiene mucho que ver el hecho de que María Casares fuera una actriz de origen español, que desarrolló toda su vida profesional en lengua francesa y escribió su único libro en esta misma lengua, aunque fuera en seguida traducida al castellano. Y así como suele figurar, al igual que otros exiliados de la guerra en Francia (Carlos Semprún-Maura, Jorge Semprún, Fernando Arrabal), en las historias del teatro francés, y muy poco en las españolas: "Exiled figures are rarely featured as objects of study within studies of their native theatrical traditions" (María M. Delgado, 2003: 93), así su relato autobiográfico ocupa muy escaso lugar en la bibliografía sobre la literatura espańola.

Por otra parte, el texto ha sido utilizado con alguna frecuencia como medio para estudiar el exilio republicano español, para sondear en la relación que la actriz mantuvo con Albert Camus, o, en términos testimoniales, para aproximarse a escritores y hombres de teatro franceses contemporáneos, pero apenas en sí mismo; circunstancia esta que hay que lamentar ya que nos hallamos ante un relato cuya calidad literaria es indiscutible. Este libro de intrincada estructura -la autora lo tilda de «barroco» (Casares, 1981a)-, único en la bibliografía de María Casares, está construido sobre un magnífico tejido discursivo que suma a la exigencia de la precisión en el uso del lenguaje, las diversas voces asimiladas por la autora a lo largo de su devenir vital: la cultura popular de raigambre familiar y la cultura del texto escrito aprendida sobre las tablas; la fascinación de María por el cine y la pintura añade, además, un matiz plástico al discurso. Todo ello para ofrecer al lector uno de los más profundos ejercicios de introspección literaria en la escritura autobiográfica contemporánea.

El escritor Alejo Carpentier en una de las primeras reseñas tras la publicación del libro, ya subrayó su valor literario, destacándolo entre la 
epidemia de memorias que se publican en ese momento, la mayor parte de las cuales «resultan de una increíble pobreza», "están muy mal escritas y no entrañan el menor mérito literario» (29 de marzo de 1980), y expresando así su admiración por las de Casares:

Ya no pensamos que es una actriz quien nos habla, sino una extraordinaria escritora, en una prosa de una riqueza, de un vigor, de una garra, absolutamente excepcionales. ¡Muy pocas novelistas de hoy podrían jactarse de poseer un señorío del vocablo, un dominio de la frase, un poder de expresión, semejante a los que aquí se imponen a nuestra atención! Por primera vez en mucho tiempo nos hallamos ante «Memorias» -llamémoslas así- que son, para empezar y ante todo, una magnífica obra literaria. (Ibid.)

Carpentier subraya la voluntad de ser que guía a la autora:

El papel de Synge, el papel de Shakespeare, el papel de Lorca o de Brecht, interpretados por la actriz, sirven para redondear e ilustrar al máximo [el] papel de mujer cotidianamente desempeńado por quien, a pulso, sin contar con más ayuda que las energías del genio propio, fue realizando su destino, entre vientos y mareas, con una imperturbable voluntad de «ser quien soy»: sum qui sum. (Ibid.)

Entre los aciertos del libro destaca el escritor cubano los «retratos pintados de mano maestra", sobre todo "los "retratos mayores", donde el modelo es visto, analizado, indagado y definido, en lo anterior y lo aparente, con una minucia proustiana»; y evoca la novela de Rilke Los cuadernos de Malte Laurids Brigge (1910), al referirse a las vivencias de María en el hospital durante la guerra civil; considera, en fin, que las mejores páginas del libro son aquellas en que la autora habla sobre el teatro.

Las declaraciones que María hizo al citado programa de RTVE «A fondo» (1981a) arrojan alguna luz sobre la interpretación de este hondo relato existencial. Distingue María en su trayectoria dos vidas distintas: hasta los 13 años (Espańa) y lo que vino después (hubo de arrinconar lo que ella era en lo más profundo de sí misma, y de ahí surgió otra María Casares); el entrevistador pregunta: «Pero, ¿dónde está la más pura y la más auténtica María Casares, en la que enterraste o en la que surgió de esa metamorfosis?». Este término clave en la constitución de sentido de Résidente privilégiée es el entrevistador quien lo enuncia por primera vez, y es aquí donde María empieza a acercarnos al sentido profundo del libro:

La primera vez que empecé a sentir verdaderamente que algo no iba, que estaba..., que en el fondo de mí había una especie de arena 
movediza, fue en los años..., fue después de una crisis muy fuerte, en plena crisis, después de los años 60 , en los años 60 . Y allí empecé a querer verdaderamente..., a tener una necesidad muy profunda de encontrar mis raíces.

Soler Serrano continúa su indagación: «Pero ¿de alguna manera las señas de identidad son las mismas? ¿o han cambiado?»; a lo que María responde:

Es lo que traté de buscar justamente cuando decidí un día al volver a España, cuando me propusieron en Francia escribir un libro. Creo que acepté escribirlo porque era el momento. Después de 40 años volvía a Espańa [...] Justo en el momento en que sentí la necesidad de buscar a través de una vida en que nunca me había parado para mirar en el fondo, si en el fondo se mira, porque está el teatro que obliga a mirar al fondo. Pero en fin, de mirar en mi vida profundamente, ni hacia atrás; no, pero en fin, nunca había sentido eso, es decir, la necesidad de buscar las raíces y algo así; pero no pararme de repente en el teatro y decirme «Bueno, ahora vamos a ver lo que pasa». Es que era una necesidad de buscar una identidad, al fin, una necesidad de buscar un sentido a la vida. ¿Es que el hecho de que en las diferentes crisis, en los diferentes momentos de crisis en mi vida, o de... que hace una metamorfosis a cada vez, la más grande quizá, la que cerraba un poco todo era la vuelta a España? Es posible.

Interpreta así la escritura del libro:

Para mí fue una aventura la historia de este libro. Fue la aventura, una aventura para buscar a través de los momentos, de las iniciaciones diferentes, porque en el fondo es un libro de iniciaciones diferentes, y a través de la crisis, a través de las mudas, de las metamorfosis... ¿dónde estaba la fidelidad? [...] Esa fidelidad que es como un río profundo que uno sigue, y cuando uno lo sigue da la impresión de que está uno en un camino justo.

En otra entrevista, concedida por la actriz a Carlos Fernández Santander en julio de 1991 (Casares, julio de 1991: 308) a la pregunta "¿Fue una catarsis Residente privilegiada?», contesta:

En cierto modo sí. Cuando me lo pidieron, al principio dije que no, pero después de mi viaje a España en el 76 pensé que necesitaba decir muchas cosas sobre mi vida, vomitarlas de una vez, y acepté la oferta de mi primer editor, Arthème Fayard. Se me propuso, recuerdo, la colaboración de otra persona que me ayudase en la redacción, pero dije que no, que era una empresa personal y que 
sólo yo podía profundizar en los grandes y pequeños episodios de mi existencia. Preferí hacerlo en francés, porque es el idioma en el que yo me expresaba desde que dejé España y en el que mi vocabulario era más rico.

Las estimaciones críticas sobre el libro hasta el momento, y salvo excepciones, han sido bastante superficiales, limitándose a afirmar la maestría de María en el dominio de la escritura así como su belleza literaria (Ortega, enero-febrero de 1997; Caballé, 1998: 132-133; Romero López, 2003: 289), pero sin indagar en el relato de vida. La excepción a este panorama es Rosa María Grillo (1998), que valora el texto en aspectos literarios como el estudio del tiempo y la importancia del desplazamiento; pone el énfasis, sin embargo, en el tema de la identidad: repara en que la fragmentación de la identidad motivada por diversas crisis (exilio, muerte) lleva a la autora a sustituir la primera persona por la tercera, y en la letra cursiva en que se expresan la corriente de conciencia, las imágenes surrealistas y las libres asociaciones; compara, finalmente, el texto de María con el de Marie Cardinal, Les mots pour le dire (1975), y concluye:

Es un texto complejo, de gran fascinación pero también de difícil lectura, radiografía de una personalidad fuerte y frágil al mismo tiempo, con seguridad la autobiografía más profunda y más sufrida de las escritas a consecuencia del exilio. [...] Poner fin a lo provisional, arraigarse, poseer algo, escribir su propia vida con consciente intención autocognoscitiva y autorreconstructiva: ese es el sentido del largo viaje que desde el desarraigo y el silencio, a través de la escritura, lleva a la reconquista de una identidad íntegra. (Ibid.: 126)

Manuel Aznar Soler, por otra parte, estudia a María como un mito del exilio teatral republicano de 1939 y la construcción de dicho mito en el imaginario colectivo del exilio, para lo cual se apoya en buena medida en Résidente privilégiée (2006).

\section{IDENTIDAD Y TRASCENDENCIA}

El objetivo del libro de María Casares es la búsqueda de la identidad, aspiración esencial en todo ser humano:

Il s'appelait Bernard Clesca [...] Il venait me proposer un moyen de rechercher une identité égarée. Un jour de novembre de la même 
année, j'ai accepté de signer le pari qu'il me présentait. [...] Tout au long de l'hiver, du printemps et de l'été, Bernard Clesca écoutait, avec cette curiosité et cette prudence passionnée -que seul peut avoir celui qui sait-comment je cherchais dans l'ordonnance des mots et une possible musicalité les méandres obscurs ou confus d'une mémoire oubliée, les signes qui me révéleraient enfin une identité. (Casares, 1980: 419)

Identidad tanto más necesaria en un ser que, como María, sufrió la experiencia del exilio, del abandono de una forma de vida, y experimentó la necesidad de volver a encauzar su existencia en otro país en una suerte de renacimiento: «Tout refaire, tout recommencer, jusqu'à l'alphabet qu'il nous fallait rapprendre à épeler. Et les manières. Et l'esprit. Et le coeur. Il fallait refouler jusqu'au néant si on le pouvait, les derniers vestiges de la personne que l'on avait été, pour devenir la même mais une autrè (Ibíd:: 136). Acto creativo y difícil ("la création si difficile que supposent un véritable amour, une existence vécue, la quête d'une identité», Ibíd:: 362) a través del cual la autora busca una segunda y nueva identidad:

En France, il me fallut apprendre à représenter d'abord et avant tout des pièces de théâtre, oeuvres de poètes et dramaturges, limitées à un choix "personnel» qui pourtant, de prime abord, comme celui qui avait présidé à l'élection de cette terre où je métais engagée, ne paraissait pas m'incomber. C'est pourtant de ce choix que part, à ce qu'il me semble, ma seconde et nouvelle identité, celle qui ma portée à «représenter» d'une certaine manière la culture française en France et à l'étranger. (Ibid.: 359)

Los meandros por los que discurre ese largo camino de búsqueda de la identidad van configurando un escrito de claro valor trascendente en el que prima la madura interpretación de la experiencia vivida, más que la experiencia misma. La lectura de la propia existencia que María Casares hace en el libro, contando con ese aliado insustituible que es el tiempo en su decurso, es una lectura en clave espiritual, sagrada (Eliade 1953: 18-23, 170), que está presente en su vida desde los orígenes:

Les fées qui ont présidé à ma naissance, l'éducation rę̧ue, ma courte existence dans les douces terres galiciennes frappées par l'eau de l'Atlantique, mont dotée de quelques trésors [...] surtout le sens du sacré, une acceptation vivante, profonde et véhémente devant la vie et la mort et l'ébauche d'un désir pour réussir l'une et l'autre, en essayant d'en chercher ou de leur donner un sens. (Casares, 1980: 69). 
En esta espiritualidad enormemente vitalista la fe ha sido sustituida por el arte:

Si j'avais la foi, je serais vite tentée par l'ascension mystique que je devine. Sans elle, c'est chez les grands poètes ou créateurs que je broute l'herbe magique pour ruminer le monde. Chez ces éternels veilleurs qui broutent, ruminent, et ont le pouvoir de nous restituer le monde transfiguré par leur grâce. Rembrandt n'avait nul besoin de quitter sa chambre pour voyager dans l'infini. Il se bornait peut-être à écouter la lumière. (Ibid.: 109)

La inclinación hacia los místicos es, sin embargo, muy notoria, en particular la que lleva a María a San Juan de la Cruz, que está presente desde la cita preliminar a I, I: «En una noche oscura, con ansias, en amores inflamada...", acompañando su viaje de regreso a España; luego su nombre es evocado junto con el de Santa Teresa, como el de un viejo conocido, a través del teatro (Ibid.: 344); además, el castellano es para María la lengua de San Juan de la Cruz (Ibid.: 395). Por otra parte, San Juan está presente, significativamente, en la primera de las ilustraciones que acompańan al texto, con un pie "Par une nuit obscure...", que evoca el espectáculo titulado La nuit obscure, representado en julio de 1968 en Avignon con María Casares, Maurice Béjart y Antonio Cano (percusiones), coreografía de Maurice Béjart, textos de San Juan de la Cruz y trajes de Germinal Casado; es una pieza-ballet donde por primera vez María trabaja sobre textos en español.

Constituyen indicios de esta lectura en clave espiritual de la propia existencia los avatares y metamorfosis por los que atraviesa la protagonista (libro II), el estado de trance que a María le es necesario para representar en escena y que ella equipara al estado de levitación en Santa Teresa (Ibid.: 177), los sortilegios (Ibid.: 261 y ss.), las reflexiones sobre la muerte, el amor y el sexo, la guerra, la madurez y la vejez en la última parte (libro III), o sobre la transmigración de las almas:

Comme ma mère, comme mon père, il est devenu [Camus] matière vive de moi-même, sans nom, sans visage, au point que l'apercevant soudain sur une photographie inattendue, ou sur une page égarée écrite de sa main, des années et des années après sa disparition, je recevais la même secousse que s'il était mort la veille. Comme mon père, comme ma mère, il m'anime; mais pour cela il m'a fallu échapper à son image vivante. (Ibid.: 242) 


\section{IDENTIDAD Y METAMORFOSIS}

Cambio, transformación, avatar, transición, mutación, muda, transmutación, alternancia, pero sobre todo metamorfosis, son los términos que resumen los cambios personales experimentados por la protagonista de Résidente privilégiée, transformaciones que son otros tantos hitos en la búsqueda y final encuentro de una identidad largamente perseguida.

Las metamorfosis le parecen a María absolutamente necesarias, porque purifican al ser humano, a través de las crisis (Ibid.: 323) o fiebres de crecimiento (Ibid.: 419) y le permiten nuevos comienzos o iniciaciones (Ibid.: 149) por medio de los cuales se va precisando su identidad. Es Cronos, dios del tiempo, el "Chargé de nous faire accepter les épreuves que représentent les différentes crises de croissance depuis la sortie du sein maternel jusqu'au renoncement ultime du vieillard, et qui sont une succession de [...] dépouillements» (Ibid.: 333). Tales iniciaciones delimitan las distintas etapas de la vida humana y suelen tener un carácter ritual:

La mayor parte de las pruebas iniciáticas implican, de manera más o menos transparente, una nueva muerte ritual a la que seguirá una resurrección o nuevo nacimiento. El momento central de toda iniciación viene representado por la ceremonia que simboliza la muerte del neófito y su vuelta al mundo de los vivos. Pero el que vuelve a la vida es un hombre nuevo, asumiendo un modo de ser distinto. La muerte iniciática significa al mismo tiempo fin de la infancia, de la ignorancia y de la condición profana. (Eliade, 1958: 12-13; véase también Eliade, 1957: 155-161)

Así lo ilustran el paso de la infancia a la adolescencia: "Il y avait eu métamorphose. Je n'étais plus une enfant» (Casares, 1980: 24); la ceremonia ritual del cortejo y casi matrimonio con Jean Servais, que marcaría el comienzo de una nueva etapa, finalmente frustrada (Ibid.: 270 y ss.); la entrada en la madurez: "Il y a la maturité, ce long passage qui accouche de la jeunesse, où l'on se nomme, où l'on se noue, où l'on s'affirme face au monde, où l'on devient un face au monde, où l'on trace ses propres limites» (Ibid.: 402); o el vislumbre de la vejez:

Vieillir-pour moi-est déjà métempsychose, et il y a dans la conquête de l'âge qui nous dépouille de nos anciens privilèges la richesse nouvelle de terres secrètes, de divines métamorphoses, d'aventures inconnues, de découvertes sans nombre, de promesses. (Ibid.: 403) 
Por otra parte, algunas transformaciones están relacionadas con el cambio de espacio: el traslado de la familia desde Galicia a Madrid («nous n’étions plus les mêmes", Ibid.: 23), el posterior desplazamiento a Francia (metamorfosis del desterrado al eterno exiliado, Ibid.: 357) o el abandono del palomar de la calle Vaugirard (final de III, 1 y 2). También la guerra produce mutaciones en el ser humano: "L'état de guerre n'est pas uniquement dans les déclarations officielles ou le couvre-feu qui vide les rues nocturnes; il est possession; il nous tient et nous métamorphose» (Ibid.: 115). Otras, en fin, son determinadas por la muerte de seres queridos; las sucesivas de su madre, de su padre, de Camus por último, suponen su derrumbamiento personal:

En 1960 une troisième coupure, affreusement inattendue, pétrifiante, est venue effectuer en moi la triple amputation à laquelle je fus soumise en quatorze années d'intervalle, les premières depuis l'enfance où le monde où je vivais se disait plus ou moins en paix; et je me suis trouvée rejetée d'un coup au plus bas de l'échelle brusquement tronquée.

C'est à ce moment-là qu'une pressante nécessité m'a propulsée à la quête de vieilles racines et aussi de racines nouvelles; et c'est depuis ce moment-là-j'avais trente-sept ans et j'en ai cinquante-six-que je cherche vainement quel est le sens de ma nouvelle existence. (Ibid.: 264)

Metamorfosis e identidad están estrechamente ligados en la imagen del ser humano habitual en el folclore:

La metamorfosis (transformación) -especialmente la metamorfosis del hombre- junto con la identidad (básicamente, también la identidad humana) pertenecen al tesoro del folclore universal de antes de la aparición de las clases. La metamorfosis y la identidad se combinan orgánicamente en la imagen folclórica del hombre. Esa combinación se mantiene de manera especialmente clara en el cuento popular. La imagen del hombre de los cuentos -que aparece en todas las variedades de folclore fantástico-, se estructura siempre sobre los motivos de la metamorfosis y de la identidad. (Bajtin, 1978: 264265)

Bajtin (Ibid.: 265 y ss.) estudia las diversas ramificaciones de la idea de la metamorfosis en la filosofía griega, los mitos antiguos, el folclore y la literatura; señala cómo, a partir de Ovidio y sobre todo en Apuleyo la metamorfosis «se ha convertido en una forma de comprensión y de representación del destino particular humano, separado del todo cósmico e histórico» (Ibid.: 267), que abarca el destino del hombre en su conjunto en sus momentos cruciales, críticos: 
Sobre la base de la metamorfosis se crea un tipo de representación de toda la vida humana en sus momentos cruciales, criticos: la manera en que el hombre se convierte en otro. Son representadas las diversas imágenes, claramente diferentes, de la misma persona, reunidas en ella como épocas y etapas diferentes de su existencia. No se da aquí un proceso de formación en sentido estricto, sino que se produce una crisis y un renacimiento. (Ibíd.: 268)

En el mismo sentido antropológico, al referirse al cuento maravilloso Eliade se pregunta si no

se ha convertido, desde muy pronto, en un "doblete fácil» del mito y del rito iniciáticos; si no ha desempeñado el papel de reactualizar, a nivel de lo imaginario y de lo onírico, las "pruebas iniciáticas». Este punto de vista no sorprenderá a aquellos que miran la iniciación como un comportamiento exclusivo del hombre de las sociedades tradicionales. Hoy comienza a extenderse la idea de que lo que se llama «iniciación» coexiste con la condición humana, que toda existencia está constituida por una serie ininterrumpida de "pruebas», de «muertes» y de «resurrecciones», cualesquiera que sean los términos de que se sirva el lenguaje moderno para traducir estas experiencias (originariamente religiosas). (Eliade, 1963: 221-222)

Y las formas populares de literatura, con lo que tienen de interpretación sobre el ser del hombre en sus avatares esenciales, le sirven a María Casares para dar forma a su experiencia vital (Lopo, 2006: 167), como tendremos ocasión de comprobar.

En la literatura culta la metamorfosis también ha sido a menudo interpretada como símbolo del crecimiento interior, v.gr. en relatos como Alicia en el pais de las maravillas (1865) y La metamorfosis (1915) (Brunel, 1974: 115-123). En la misma dirección, Marina Warner (2002: 90, 9293) estudia la metamorfosis en literatura como un medio de hablar del yo; destaca su presencia desde la antigüedad tanto en el relato popular como en el mito y ejemplifica el tema con las Metamorfosis de Ovidio y el Asno de oro de Apuleyo, enumerando los tipos de transformaciones más habituales en el primero: en animal, en piedra, en elemento vegetal; de todas ellas las más importantes de todas son las que sufren los seres humanos, que en su nueva forma suelen conservar algunas cualidades de la existencia anterior, y de entre ellas una de las más frecuentes es la de convertirse en crisálida de la que luego emerge la mariposa, acto similar pero no igual al de la procreación ovípara, metáfora que se utiliza de modo recurrente para ilustrar las transformaciones del ser humano: 
Pupation, the weaving of the cocoon, followed by the sudden, wondrous emergence of the imago -the butterfly-from the chrysalis, offered, in the classical repertory of symbols, a correlative of hatching, with the significant difference that while hatching produces like from like, as does viviparous birthing, pupating produces something almost entirely unpredictable: the parent in this case do not ensure any recognizable feature in the offspring. Many metamorphic tales, classical or classical by emulation, follow this pattern of arriving at anagnorisis or recognition through of series of concealments, or even disfigurements, of revealing true, inner character through a series of outer changes of shape. The traditional storytelling of a hero or heroine who journeys through numerous ordeals, through misprisions and neglect, finally to arrive at selfhood, follows this model of metamorphosis: the protagonist's true self generates itself in this proper character after undergoing several transformations; the larger transformation of their circumstances and the appearance of the person's fullness of being unfolded through several smaller transformations. (Ibid.: 84-85)

A esta metamorfosis, que implica la representación de la vida humana en sus momentos cruciales de crisis y renacimiento para alcanzar el crecimiento interior, hay que añadir la que es inherente al teatro. Ya Nietzsche en El origen de la tragedia escribía: "Este proceso del coro trágico es el fenómeno dramático primordial: verse uno transformado a sí mismo delante de sí, y actuar uno como si realmente hubiese penetrado en otro cuerpo, en otro carácter. Este proceso está al comienzo del desarrollo del drama.» (Nietzsche, 1871: 83). En la misma idea insiste Ortega y Gasset en su conferencia Idea del teatro:

El cuadro es imagen porque es permanente metamorfosis -y metamorfosis es el Teatro, prodigiosa transfiguración [...] Lo que vemos ahí, en el palco escénico, son imágenes en el sentido estricto que acabo de definir: un mundo imaginario; y todo teatro, por humilde que sea, es siempre un monte Tabor donde se cumplen transfiguraciones. El escenario del Teatro Doña María es siempre el mismo [...] Sin embargo, recuerden ustedes todas las innumerables cosas que ese breve espacio y ese pobre material les ha sido [...] Lo mismo acontece con el actor. Ese mismo y único actor ha sido para nosotros incontables seres humanos: ha sido rey y ha sido mendigo, ha sido Hamlet y ha sido Don Juan. El escenario y el actor son la universal metáfora corporizada, y esto es el Teatro: la metáfora visible. (Ortega y Gasset, 1946, ed. 1958: 40-41). 
Años más tarde Henry Gouhier vuelve sobre el particular en La esencia del teatro, citando a Nietzsche, y añade:

La voluntad de metamorfosis aparece bajo múltiples formas que no son siempre teatrales, ni siquiera estéticas; se manifiesta hasta en los repliegues de la conciencia de sí misma, no siendo más que una actitud normal y universal del pensamiento del hombre respecto al hombre. En el teatro, la metamorfosis significa mucho más que vivir otra vida con la imaginación, como lo hacen el autor y el lector de ese sueño bien trabajado que es una novela; concluye en la escena donde los personajes se convierten en papeles, en personas reales cumpliendo un papel [...] Esta metamorfosis, cuyo irresistible atractivo sufría Henry Becque, no es ni la de un alma evadida, ni la de un cuerpo disfrazado, sino la segunda vida del comediante [...] La metamorfosis del comediante crea un universo nuevo, que debe existir sin fisuras, para ser un nuevo universo. (Gouhier, 1956: 4344)

La misma idea es expresada en términos metafóricos por María Casares:

Comme notre corps vivant qu'il faut nourrir pour vivre, le théâtre, creuset magique, broie, avale, assimile, transforme toute pâture en humeurs, chaleur, énergie, sang neuf; ce sont là les matériaux que le comédien malaxe pour sculpter et animer ensuite les personnages inventés par l'auteur. Mais pour que la métamorphose soit posible, pour qu'il y ait vie nouvelle, il faut à l'ogre une pâture vive. Avec nos instruments -notre corps, notre voix, le visage, le savoir -il nous faut aussi et avant tout l'apport de sèves nouvelles, et cet apport peut aussi bien nous venir d'un grand malheur qui se transfome -au jeu-en allégresse, que du plus éclatant bonheur qui-au jeu-nous porte à compatir avec les plus cruelles douleurs; mais pour que cela soit, il nous faut éprouver dans notre chair même plaisirs et douleurs, vivre, toujours, ces avatars que je ne connaissais point encore à Madrid, quand je croyais que jouer c'était exulter, extérioriser ses joies, sa peine, à mesure qu'elles venaient, à peine voilées derrière un masque, sans en rien transfigurer. (Casares, 1980: 347)

E ilustrada en modo preciso por André Schlesser, compañero y esposo de María, y sobre todo hombre de teatro:

Lutin, regard qui veille, alternance, transition, mutation, métamorphose- il était le temps de la représentation. Bijou, parade, volte-face, va-et-vient, caprice, diversion, voltige, fluctuation, sérénade, deus ex machina-il en était l'harmonie. (Ibid.: 428) 
Proceso por tanto primigenio el de la metamorfosis, que apunta hacia la comprensión antropológica del ser humano tal como se expresa en las diversas formas de cultura popular (cuento, copla, canción, romance) pero también en las de literatura culta (el teatro entendido en su sentido más ancestral, al modo de la tragedia griega). A través de ambas accede María al encuentro de sí misma.

\section{LOS AVATARES DE LA VIDA}

El libro II lleva por título general "Avatars», esto es «changements, transformations ou métamorphoses d'une personne ou d'une chose qui en a déjà subi d'autres»; el término tiene un claro sentido animista que deriva de su origen en la mitología hindú, y que invita a interpretar la existencia en un sentido trascendente. Y es que la búsqueda de la propia identidad por parte de María Casares en Résidente privilegiée se expresa a través de sucesivos avatares, siendo algunos de los más significativos los que se glosan en este segundo libro. En el primer capítulo de este el avatar es el espejo («miroin»), que a su vez remite a las transformaciones en patito feo («canard laid»; la fea oruga que luego forma el capullo) y capullo («cocon»); en el segundo las "Transmutations» se reflejan en los símbolos de la mandrágora («mandragore») y la ninfa («nymphe»-crisálida o pupa y luego mariposa-); en el último, «Sortilèges», una "Cérémonie rituelle» y una trágica relación entre "La fiancée et la mort», dan forma metafórica a los dolorosos cambios experimentados por el ser humano para purificarse y avanzar en la configuración de su propia identidad.

El espejo es un símbolo universal de la búsqueda de la identidad; para María es principalmente el del Teatro de los Mathurins en 1942, en el arranque del libro II, cuando acaba de iniciarse en la representación en lengua francesa: «Le soir du 21 novembre 1942, peut-être parce que c'était la date de mon vingtième anniversaire, je me suis arrêtée un instant à regarder, perplexe, l'image que me renvoyait la glace de ma loge au théâtre des Mathurins" (Casares, 1980: 135); precedida por estas palabras se abre paso una extensa retrospección en que se resumen los seis años anteriores, a partir del exilio de 1936; en este recuerdo asoman en varias ocasiones las referencias a ese espejo que lo hace posible (Ibid.: 175), hasta finalizar el capítulo I de este segundo libro donde comenzó, ante el mismo espejo (Ibid.: 189).

Este símbolo constituye sin duda un punto de anclaje en la historia de María, porque a través de él se recuperan los inciertos y dolorosos primeros años del exilio y comienza su indagación en el conocimiento de sí misma y del teatro. No funciona, salvo excepciones, como una de las metamorfosis de 
la protagonista; es sólo un medio de acercarse a la búsqueda de la identidad perdida y necesitada de una reformulación. Es lo mismo que representa el mito de Narciso, enamorado de su propio reflejo en el agua e incapaz de alcanzarlo, muriendo de pasión hacia sí mismo y metamorfoseado finalmente en flor; representa Narciso la búsqueda consciente del propio yo; y precisamente al actor alude María como «nouveau Narcisse» (Ibid.: 347). El espejo tiene, además, un significado específico en relación con la mujer; Bram Dijkstra (1994: 129-150) lo interpreta como medio de reflejar la identidad femenina, por lo que la mujer suele representarse ante el espejo en un perpetuo acto de autorrefuerzo; la mujer se configura así como "Narcisa», encarnación femenina de lo que había sido el egocentrismo masculino.

Hay otros espejos en el libro que hablan de identidades rotas, como el que aparece en el libro I, 2, ese simbólico espejo veneciano que se cae y se rompe cuando estalla la guerra civil: «Las familias estallaban como el espejo en campos enemigos» (Casares, 1980: 104). O aquellos otros que necesitará para encontrarse tras la quiebra interior por la muerte de su padre y de Camus: la bola de oro y le miroir/glace.

La bola de oro instalada en el techo de su habitación refleja a la propia María, perdida dentro de sí, tratando de encontrarse en el espejo de la escritura que ahora se ofrece enigmática:

Elle regarda encore son image dans la boule, obèse au centre de cette chambre qui fuyait vers elle, qui rétrécissait pour s'engouffrer en elle, minuscule grosseur au centre de la boule qui avalait la chambre dans son cahier ouvert sur son ventre. Il y avait certainment matière à chercher sur ces pages reflétées au plafond, dans les lettres à peine visibles qui semblaient sordonner loin, très loin, en énigmatiques réponses [...] Devant la page enluminée au plafond, elle se mit à rêver de libellules; des signes quielles mettent sur les feuilles des nénuphars, parcheminées par la brûlure du soleil sur la rivière quand elles s'y groupent accouplées en écriture secrète comme les lettres d'un mystérieux alphabet. (Ibid.: 341)

Y nuevamente el espejo muestra su desorientación, su fragmentación interior reflejada en el uso de la tercera persona distanciada:

Prise de vertige, elle ferma les yeux et appuya sa poitrine contre le marbre froid de la cheminée; quand elle les rouvrit, elle se vit devant elle, dans le miroir. Deux grands yeux étonnés et attentifs la regardaient; mais ce ne fut là qu'une image fugitive, devinée plutôt qu’aperçue [...] Elle retrouva le vieux reflet, et une page d'un journal intime qui semblait lui appartenir lui revint, claire, à l'esprit:

-C'est alors que la grimace a commencé. Elle a bien modelé chaque 
trait du visage. [...] Elle fait le masque que je regarde dans la glace masque revêche, dur, sec, avec toutefois quelque mollesse qui apparaît ici et là. La vilaine grimace qui refuse la souffrance au prix même de cette indéfinissable vulgarité qui tremble devant les grandes joies. (Ibid.: $337-$ 338; la redonda está en el original)

El espejo está también presente a través de un instrumento óptico, ese espejo múltiple que configura el caleidoscopio, metáfora del teatro:

Les informations qu'on y apprend sur le monde et ses habitants font mes connaissances; et mon expérience de la vie serait bien piètre s'il n'y avait pas eu, pour me l'enseigner, le kaléidoscope précipité et grossissant qui la reflète pour moi au théâtre. J'ai connu, en scène, plus de problèmes, de difficultés, d'incidents, d'accidents, d'échecs, de triomphes, de plaisirs, de joies, d'extases, d'événements de toutes sortes et de toute envergure, que l'on ne pourrait en accumuler dans la plus riche des existences. (Ibid.: 344)

Hay también otros espejos metafóricos. El del teatro y el de la vida:

Comme au théâtre, chacun de nous est le récipient creux où passe le flux de la vie et les grands privilèges du comédien comme sans malédiction se tiennent dans la prérogative qui lui a été donnée pour disposer-afin de vivre doublement- de deux vases qui ne font qu'un parce qu'ils sont communicants. Sa destinée consiste à garder à même hauteur les deux niveaux; sa chance, sil reste attentif d'un côté comme de l'autre, est de pouvoir sans cesse constater dans ce double miroir le trop plein ou les manques. (Ibid.: 348)

El espejo que es la otra persona, ya se trate de una mujer:

Après des échanges qui mévoquaient une étrange danse avec ma propre image à travers un miroir, je me suis retrouvée, perplexe, entière, à observer devant moi un être distinct de moi-même et le même, une créature vivante qui réclamait la part d'abandon sans laquelle le souffle de l'absolu reste insaisissable et l'unité recherchée impossible (Ibid.: 184),

ya de un hombre, Camus: "Dans la même position, derrière moi, à un pas de moi, comme le reflet, dans une glace, Camus retourné sur moi, me regardait, (Ibid.: 325); o André:

Il mapporte l'oubli de moi-même. Je disparais devant lui: je m'esfume. Le miroir qu'il me propose me renvoie un reflet où la grimace s'est transformée en oubli. Devant lui je deviens le miroir même. Ou 
l'ouverture vitrée à travers laquelle je le regarde, loin, très loin, regarder le monde et me regarder. (Ibid.: 421)

Más profunda esta última mirada, que le permite incluso transformarse en el espejo mismo (metamorfosis en objeto).

El orden de estas metamorfosis parece ser el lógico causal: desde la larva (canard laid), pasando por el capullo (cocon) hasta la ninfa, para desembocar en mariposa (madurez: la narradora llama a la cojita que aparece en el libro III "papillon piégé par la lumière», Ibid.: 413)

El pato feo (canard laid) es el primero de los avatares importantes de María en el exilio, adaptación de la figura del patito feo («vilain petit canard», Ibid: 135) del conocido cuento de Andersen, con una cita del cual se abre el capítulo 1 del libro II. El gusto por los cuentos es una herencia de la infancia, de los relatos contados por la madre y por la tía Cándida:

Avec les sirènes, les reines, les princes charmants, les elfes, les fées de maman, et les revenants, les monstres, les démons, les charrettes fantômes et la Sainte Compagne de ma tante, il y aurait de quoi composer un long recueil, bien équilibré, où toutes les forces obscures de la nature humaine seraient représentées. (Ibid:: 65)

Las referencias a este avatar son numerosas en el libro; en p. 149 se evoca su torpe manera de caminar «la démarche syncopée et bancale que javais toujours imaginée pour le vilain petit canard du conte d'Andersen» (el paso desmañado y torpe, a trompicones, con el que María sigue el de quienes se forman a su lado con más seguridad, por el dominio de la lengua). Historia la del patito feo de trascendencia universal, emblema de las personas desplazadas como la propia María:

une histoire qui, peu à peu, se reproduit de plus en plus partout dans le monde entier, afin de le remplir de canetons laids, accourus des quatre coins de l'horizon pour se déverser en tous lieux, pour apprendre une nouvelle langue et une nouvelle forme d'exister tout en essayant de demeurer fidèles à ce quills étaient, pour devenir peu à peu les seuls représentants de cette notion qui se perd de fidélité, et pour chercher -nouveaux nomades- un sol où pouvoir l'implanter; mais dont la véritable identité-quoi quil arrive et quoi quils fassent-restera toujours celle de personnes déplacées. (Ibid.: 357)

También pertenecen a la especie del «canard laid» el editor Bernard Clesca (Ibid.: 419) y su esposo André Schlesser: "Enfant adopté par sa famille et Paris, la ville où il est né, il a ceci de commun avec les canards laids: il est 
profondément convaincu que la société où il vit ne lui doit rien, mais qu'il reste en revanche toujours en dette avec la société» (Ibid.: 424).

Pero el cuento del patito feo relata, además, la historia de una transformación, y de una iniciación (Ruiz Mata 2003), como las de la propia María a lo largo de los diversos avatares de su vida.

El capullo (le cocon) es, metafóricamente, el apartamento de la calle Vaugirard, que ha servido de refugio a María y su familia y a sus allegados durante 30 años (hasta 1971): "c'est le trou où je m’isole, le cocon où je me refais" (Ibid.: 357); también llamado "aire, nid, guérite, phare, colombier» (Ibid.: 351), "pigeonnier, devenu port, nid, pays, foyer, patrie, terre haut située ouverte au ciel dans le cour même de la cité» (Ibid.: 366). Asimismo, es el capullo, también metafóricamente, ese periodo de la vida de María que corresponde a la iniciación en el teatro y en la sexualidad.

La mandrágora, avatar que se ilustra en el Libro II, cap. 2, cuyo sentido legendario se aprovecha en estas memorias (su raíz tenía la forma del ser humano, y sus energías podían dirigirse lo mismo hacia el bien que hacia el mal), representa al ser colectivo atenazado por la guerra, los miedos innombrables: "Là-ils se tenaient tous les quatre-debout-entassés contre la porte de l'escalier de service- les uns contre les autres comme de gros agneaux chimériques -agglutinés en une imposible mandragore" (Ibid.: 217); "la mandragore nous nouait tous autour de ses racines, et, sans que rien fût formulé, introduisait en chacun de nous les protubérances d'un monstre que nous n'osions ou ne savions nommer.» (Ibid.: 227). El recuerdo del monstruo reaparece años más tarde durante una estancia en la costa francesa cuando escucha a un grupo de hombres hablar en alemán: "En les écoutant, un bizarre spasme vint crisper ma mémoire comme si, au creux de mes entrailles, là même où sourd l'innocence, une plante poussait ses racines fourchues pour y nouer en forme d'atroce poupée désarticulée le signe retrouvé d'une pestilente mandragore» (Ibid.: 381).

Otra evolución en el libro II, 2 es la que lleva a María a convertirse en ninfa, esa última fase de la metamorfosis del insecto, previa al momento en que ha de transformarse en mariposa, a la madurez en fin; en ella se resumen los tres años de teatro en Mathurins, de cine y grabaciones en la radio (19421945) y la imprescindible relación con Albert Camus.

Muchos otros cambios ilustran el proceso de crecimiento interior de María Casares, mutaciones en elemento vegetal, en animal, en ser fabuloso y muy rara vez en objeto. Las más interesantes son las que se cifran en la adquisición de otra entidad humana; tras la relación con Camus son tres: las de novia, amnésica, y cojita (por este orden), todas las cuales implican una pérdida y una limitación (amputación). 
"La fiancée et la mort» es el título del último capítulo de libro II, uno de esos sortilegios o influencias mágicas que operan sobre la vida de María. Ella es la novia, ya definitivamente, de Camus, y la muerte es la del padre; el sortilegio permite que su padre se le aparezca justo antes de morir, como una premonición de su inmediato fin, en una aparición irreal en la que sus pies no tocan el suelo; premonición esta que es habitual en el folclore. La figura de la novia acaba de perfilarse en el libro III, cuando María esboza en sus escritos las figuras de la amante y la novia, siendo esta "qui me révélait pourquoi l'on pouvait songer à se marier» (Casares, 1980: 398); luego visualiza ambas figuras: Anne, la novia gitana virginal (tal vez inspirada por la novia de Bodas de sangre (1933), que huye con un hombre casado, siendo perseguidos los amantes por el novio y la muerte, o tal vez por Annie, la protagonista gitana del film «Hot Blood» de Nicholas Ray, 1956), y la amante, sin nombre, "gibier de nos villes (...) Dame aux camélias 1967» (Ibid.: 399). María, que se ve a sí misma atrapada entre ambos tipos, opta finalmente por la primera, esto es, por el matrimonio: "Il s'agissait de se reconnaître en Anne, la petite vierge gitane, et en sa vérité» (Ibid.: 405)

Tras la muerte de su padre y de Camus, María experimenta una quiebra interior que le provoca una absoluta desorientación vital, perdiendo la conciencia de sí misma, lo que se traduce en la pérdida de la palabra; se convierte en una amnésica que no logra siquiera recordar su nombre (porque han desaparecido quienes la llamaban por el mismo), y su empeño incesante es bucear en la propia identidad a la búsqueda del nombre; el uso de la tercera persona narrativa y los sueńos irreales de la protagonista tratan de dar cuerpo a esa indagación. Es una etapa de purgación, de hondo sentimiento de vacío existencial («no man's land», Ibid.: 342), en que María experimenta una sensación de desposesión de sí misma (Ibid.: 364, 366); el dolor de esta etapa de su vida se anticipa en el discurso del relato mucho antes de que llegue su tiempo:

Il reste, cependant, la traversée sur les sols stériles de la sécheresse du cour; alors, quand ils se sont présentés, devant l'horreur ou après la perte toujours prématurée des êtres les plus aimés et les plus nécessaires, j’ai fui comme une bête. Oui, confrontée aux ravages d'un horrible "no man's land» qui trouait soudain le monde, inapte à vivre comme à me laisser mourir, j'ai dormi. Je me suis échappée par l'orifice de longues et lourdes nuits de sommeil dont les bienfaits naturels ramenaient rapidement en moi la poussée vitale. Et amputée, boiteuse, manchote, cul-de-jatte, je recommençais. Je me suis débattue comme une forcenée dans le silence buté pour passer outre; pour bâillonner, enchaîner, maîtriser le cri spasmodique de la souffrance. Et c'était alors la chasse aux souvenirs pour 
les abattre. Enterrement sur enterrement. Et je t'enfonce bien loin dans le néant, sous la terre. Derrière la terre. Et j'entasse des montagnes pour boucher les trous et je piétine et je tasse et je remblaie pour que tout disparaisse, pour continuer, pour recommencer, pour retrouver innocence et liberté. (Ibid.: 111-112)

De esta fase resulta una transformación sustancial en la existencia de María Casares, que deriva hacia la madurez, con un cambio de espacio y de pareja, para recomenzar partiendo de cero: «Finis les trous! La plaine. On recommence à zéro» (Ibid.: 341); experiencia que refleja muy bien esta impactante imagen del retorno al origen, "regressus ad uterum» (Eliade, 1953: 164-169; 1958: 89-101):

Recroquevillée sur moi-même dans un coin comme un énorme foetus, le ventre ouvert par un invisible scalpel, à la fois nouveau-né et mère, attendant la première gifle qui me fasse pousser le cri d'une naissance que j'ignorais, je restais là, aveugle, sourde, tuméfiée, sans rien savoir de rien ni même que, dans cette affreuse douleur de mort, j'enfantais d'une femme-moi-au moment même où je prenais conscience de la condition qui m'était posée. (Casares, 1980: 362)

Paralelamente a este proceso, la identidad se va definiendo en María mediante la paulatina recuperación de su nombre, un nombre en variantes; primero los nombres civiles, los que figuran en la Carte de séjour de Résidente privilégiée: Maria Casarès (en francés; con el acento grave en la è para no perder la -s final de su apellido), María-Victoria Casares-Pérez (en español); luego los familiares: María, Vitoliña y María Victoria (Ibid.: 395). Estos nombres se precisarán más adelante con el añadido de un nuevo apellido en el documento de identidad que adquiere al casarse con André Schlesser: Maria Schlesser (Nom), Maria Casarès (pseudonyme;), María-Victoria Casares (nom de jeune fille) (Ibid.: 420).

La amnésica da el relevo a la cojita en la búsqueda de la identidad a través del nombre: "L'amnésique qui cherche son nom oublié dans le dictionnaire y trouve l'infirme qui cherche, elle, pour se nommer, l'âme jumelle» (Ibid.: 411), una diáfana representación de esa mujer que ha sufrido diversas amputaciones a lo largo del libro. Parece uno de sus cuentos de infancia, una fábula sobre el hallazgo del amor verdadero, ya que relata su encuentro con el vagabundo Ariel, que no es otro que el que luego será su esposo, André Schlesser: el poder de la cojita para adherirse a la tierra y las alitas de Ariel se cruzan; ambos son seres metamórficos (también Ariel; en Ibid.: 413, 421).

El personaje de la cojita está sin duda inspirado en un poema de Juan Ramón Jiménez al que la autora se refiere en p. 88 ("les peines de la petite 
boiteuse de Juan Ramón Jiménez»)). La soledad de la cojita del poema juanramoniano, incapaz de alcanzar su muleta con la rapidez suficiente para poder jugar con los niños es la misma soledad de la cojita descrita por María, maltratada por los seres de la tierra y finalmente acogida por un ser que no es de ella sino del aire: el vagabundo Ariel.

\section{LOS AVATARES DEL TEATRO}

El discurso autobiográfico de María incide en diversos momentos en la metamorfosis consustancial al trabajo de actriz, verbi gratia:

J'ai habité les palais de la Renaissance, les châteaux du Moyen Age, les ruines de l'Empire aztèque. J'ai chevauché les montures des Amazones. Je suis passée à travers les portes closes. J'ai traversé les siècles. J'ai marché de l'autre côté des miroirs. J'ai survécu à la guerre, à la peste, à la mort même. J'ai été la Mort, et la Vie, et l'Homme, et la Femme, une Plante, un Serpent, une Île dans l'océan Indien. J'ai vécu cent destins. J'ai souffert des plus hauts cas de conscience. J'ai tué. J'ai trahi. J'ai été bourreau et martyre. Sadique et masochiste. Tyran et esclave. J'ai représenté les plus belles histories d'amour. (Casares, 1980: 344)

Entre los muchos personajes que María Casares representó a lo largo de su carrera teatral algunos aparecen ilustrados en las imágenes que acompañan al libro en su edición francesa (en la española el número de ilustraciones se reduce considerablemente). La parte gráfica del libro entremezcla fotografías, cartas, recortes de periódico y objetos significativos en la vida de la autora y en el desempeño de su profesión. Las fotografías registran gestos congelados de algunos de los papeles encarnados por María Casares, algo particularmente interesante en relación con una actriz cuyo rostro se compromete por entero en el acto de la representación:

son visage se transforme, il se déforme, il rejoint sans réserve les plis du masque ancestral par lequel la douleur, la panique ou la joie sont signifiées, il retrouve spontanément une image de la passion, qui n'est pas d'ordre métaphysique, mais séculaire, mémorial. Voyez les grands masques antiques, disposition excessivement anguleuse des sourcils, des rides et des commissures. Ceci est une leçon: il faut engager le visage, tout le visage, dans l'aventure du théatre, il faut bouleverser ses tissus profonds, renoncer sur scène à la beauté pâteuse ou éthérée des studios d'Harcourt, pour retrouver, comme le fait Casarès, la beauté d'un mouvement total. (Barthes, 1954: 494) 
Las ilustraciones para el libro I son todas fotografías personales, excepto una, la que abre el conjunto, que representa una impresionante imagen de María durante la ejecución de La nuit obscure de Maurice Béjart, a la que ya he aludido.

Para el libro II son varias las fotografías que figuran a María representando diversas obras teatrales y sólo una cinematográfica, ya que si bien se confiesa apasionada y maravillada espectadora del séptimo arte, también afirma que no llega nunca a satisfacerle como el teatro. No obstante, rodó varios filmes, sobre todo en las décadas de los 40 y los 50; entre todos los papeles que desempeńó sin duda el más relevante fue el de la duquesa Gina de San Severina en el film La cartuja de Parma, dirigido en 1948 por Christian Jaque, papel por el que obtuvo el premio a la interpretación femenina en el festival de Locarno (Dussane, 1953: 57-58; Zumalde, 2002); la imagen lleva un pie que reza: "La Sanseverina ou "la face de Brute"», que es un homenaje a su padre Santiago Quiroga, como se deduce del fragmento de una de sus cartas:

Con tu carta viene un retrato de "La Casares» disfrazada de Sanseverina. ¡Caray con la Casares, con la Sanseverina y con el retrato! De todas las caras de bruta que te he visto exhibir en tu vida artística, esta es la más perfecta -por más bruta- de todas ellas. ¡Qué nariz, categórica y apatatada, llena aún del perfume de un buen vinazo de Toro, denso y rojo como sangre! ¡Qué quijada, fuerte y dura como la de un dictador! ¡Qué aire espetado, absolutamente extremeño, ajeno ya a los Casares y a los Corrales y a la Coruña y a Galicia para dejar paso a Cáceres y los Asensios, tus abuelos maternos! (carta escrita en París el 14 de abril de 1947, en Lopo, 2008: 54)

Las otras ilustraciones para el libro II corresponden a tres obras teatrales: - El príncipe que todo lo aprendió en los libros (1909) de Jacinto Benavente, una obra de teatro para niños, fue la primera obra teatral en que María intervino como actriz, siendo aún una niña, durante su etapa de estudios en el Instituto-Escuela; su papel fue el de hada o hechicera que esgrimía su varita mágica, papel especialmente querido para María por dos razones: porque fue un ejemplo de actuación pura, exenta del trance habitual en sus actuaciones posteriores:

un univers, un pays que je découvrais peu à peu, libéré de tous et de tout et de moi-même, et où-seules-demeuraient la fillette qui jouait le rôle du prince -Isabelita- transformée déjà par les soins de mon imagination en jeune homme bien avant d'avoir endossé le costume, et cette autre inconnue -moi-qui, à travers mes propres oripeaux et cette 
canne que j'avais souhaitée pour me tenir lieu d'appui ou de baguette magique, cherchais la voix, le port, la démarche, le comportement d'une vieillarde centenaire -fée ou sorcière?-qui se cachait en moi-Dans un lieu vide, qui se peuplait de jour en jour de vie et de mystère-Dans le creuset isolant d'un état de parfaite disponibilité, d'acuité sensible et sensitive, de virginité, de total accueil. (Casares, 1980: 91-92)

Y porque los seres mágicos están muy vinculados a su Galicia natal y a su infancia, especialmente las meigas, que dan título al capítulo 1 del libro I ("As Meigas»), personas dotadas de poderes extraordinarios y capaces de pactar con el diablo; meiga es en estas memorias su madre Gloria Pérez, que obra la magia cotidiana de dar armonía y encanto a la vida de cuantos la rodean; también María se considera meiga en algunas páginas del libro ("changée en sorcière par le vouloir du poète et la magie du théatre», Casares, 1980: 344), y quizás aplique sus dotes de hechicera para metamorfosearse a sí misma (Caro Baroja, 1969: 58). Por ello la autora subraya la importancia de esa varita mágica de la obra de Benavente en el título de una sección del libro I, 2: «La baguette du sorcier».

-Les paravents (1961) de Jean Genet, obra de teatro del absurdo, fue representada en el Teatro de l'Odéon en abril de 1966 bajo la dirección de Roger Blin, si bien había sido publicada en 1961 y representada por vez primera en Berlín en junio de ese mismo año, tras haberse prohibido en Francia. La obra, de contenido político, se refiere a la historia reciente de Argelia, y fue tachada por algunos de anticolonialista y de hacer una caricatura del Ejército; en ella Genet toma partido, de modo claro, por los argelinos; de ahí que la controversia rodeara su estreno en Francia y que el Ministro de Cultura, André Malraux, tuviera que intervenir para que la obra no fuera prohibida. María, que representaba el papel de la Madre, hubo de sentirse a gusto con una dramaturgia experimental como la de Genet, que ponía a prueba las cualidades del trabajo de actriz, además de haberse visto probablemente afectada por un tema, el de Argelia, que había sido muy importante para Camus. La colaboración con Genet supone para María un regreso a "ma terre», la tierra de Sancho y del Lazarillo, «celle où je me reconnaissais» (Casares, 1980: 395), y la afronta con una actitud de profundo compromiso: "je n'ai jamais été confrontée à un texte théâtral qui ait exigé de moi un tel engagement ni un tel courage pour m'y engagen" (Ibid:: 396), que acepta fascinada:

J'ai accepté avec ardeur, crainte, fascination, avec la fièvre qui doit saisir l'explorateur quand il s'engage dans un paysage flamboyant de fêtes nocturnes, de magies blanches, de sirènes précieuses et pierres miroitantes 
- améthystes- aventurines- jaspes- oils de chat-et où, seuls, quelques signes sont là pour parler le langage familier. (Ibid.)

-Solness le constructeur (1892), una tragedia de Ibsen, fue representada en 1943 con una versión bastante particular del personaje por parte de María, que representa el papel de la joven Hilde Wangel (Dussane, 1953: 35); es la segunda obra que interpreta sobre la escena, en esta ocasión junto con Jean Marchat, que protagoniza una divertida anécdota el día del estreno (Casares, 1980: 209-210).

Las imágenes que ilustran el libro III vuelven sobre el teatro:

- La mante polaire (1977) de Serge Rezvani, dirigida por Jorge Lavelli, se estrenó en 1977 en el Théâtre de la Ville, y en la obra María encarna el papel de Catalina II. Es el primero que la actriz representa tras su vuelta de España y haberse recuperado de una hepatitis, aún débil, y tras dos años de ausencia de la escena parisina; poco después empieza a escribir Résidente privilégiée.

- Le malentendu (1941-1958) de Albert Camus, una tragedia moderna, fue representada en 1944 en el teatro Mathurins, desempeñando María el papel de Marta, la hija de la hostelera; la obra fue mal acogida por la crítica (Dussane, 1953: 39-44; Delgado, 2002: 98). Las sucesivas representaciones de la misma se desarrollaron en paralelo con la relación amorosa entre María y Albert; Delgado $(2002,99-100)$ ha señalado el influjo de María sobre la escritura de Camus más allá de los papeles que aquella desempeñó en las obras del escritor (Le malentendu, Caligula y L'État de siège). La interpretación del papel de Marta hay que hacerla en clave personal, muy en sintonía con el objetivo que guía este trabajo: "Dans L'Étranger comme dans le Malentendu comme en lui, je ne cherchais encore que moi-même» (Casares, 1980: 241).

- La dévotion à la Croix de Calderón fue traducida por Camus para el festival de Angers en 1953 y dirigida por Marcel Herrand; con ella María representa en Francia, por vez primera, una pieza del repertorio español encarnando el papel de Julia, en la imagen vestida de hombre. Delgado (2002: 100) afirma que María colaboró durante los años 50 con Camus en las traducciones de La devoción de la cruz de Calderón y El caballero de Olmedo de Lope, con las que se presentaron al Festival d'Art Dramatique de Angers en 1953 y 1957, respectivamente. Un signo, el de la cruz, que parece acompañarla más allá del teatro, cuando recuerda la devoción de André al mismo (Casares, 1980: 429).

-Las dos últimas ilustraciones corresponden a dos tragedias de Shakespeare: Macbeth, dirigida por Jean Vilar y representada con el Théâtre National Populaire en 1954 en Avignon, en la que desempeña el papel de Lady Macbeth, y Hamlet, en 1960, bajo la dirección de Claude Barma, en el 
Grand Théâtre de la Cité de Carcassonne, en que asume el papel de Ofelia; de la primera recuerda los ensayos con su amigo Pierre Reynal: "Las escenas de Macbeth que "pulíamos" juntos para el Théâtre National Populaire» (Ibid.: 374). María debió de leer a Shakespeare muy joven, lo que alimentó su gusto por el teatro; en una entrevista con Manuel Rivas en 2001 señala la actriz su devoción por el dramaturgo inglés del que dice: «iÉ tan actual en todo! [...] O que me fascina de Shakespeare é que é un visionario. Eu penso que estaba en contacto coas meigas» (Rivas, 2001: 14); confirma que al exilio se llevó como parte de su equipaje las obras de Shakespeare: «Pillei o libro, fixen o mesmo xesto e comecei a ler. Fiquei embruxada.» (Ibid.: 15), libro que cita en su autobiografía (Casares, 1980: 99, 140). Por tanto, es evidente que hay una profunda afinidad entre la mitología y el folclore de su Galicia natal y el teatro de Shakespeare, que lo convierte en un referente clave de su obra teatral y de su escritura; además, el personaje del vagabundo Ariel (libro III, II), que conforma literariamente a su esposo André, es sin duda un homenaje último a la obra de Shakespeare (La tempestad).

Como se deduce de los textos y de las ilustraciones, María desempeñó en el curso de su profesión de actriz todo tipo de personajes (históricos y comunes), de todas las edades (jóvenes, maduros y ancianos), lo mismo del teatro clásico que del contemporáneo, buscando siempre la novedad, el desafío que supone ejecutar papeles cada vez diferentes. En este respecto son interesantes algunos de sus comentarios a Jacinto Soriano; cuando este le comenta: "Jean Genet era partidario de una sola representación», María contesta: «Exactamente y de ahí venía esa enorme simpatía que teníamos el uno por el otro. Lo que yo quiero decir es que éste me parece el sentido más auténtico del teatro. Hablo, naturalmente, de las grandes obras» (Soriano, 1988: 60); en el mismo sentido afirma poco después: "Yo no he tenido nunca un sistema de intrepretación. Y esto viene por la misma razón que te decía, por el miedo a la esclerosis y el ansia de virginidad permanente» (Ibid.: 62).

El sesgo trágico es otra de las constantes de María en el ejercicio de su profesión, tal y como se pone de manifiesto en los textos y en las ilustraciones; y es que María Casares fue una actriz eminentemente trágica como señalan Dussane (1953: 32 y ss.) y Roland Barthes (1954: 493): "L'art de Maria Casarès possède le pouvoir capital de la tragédie: fonder le spectacle sur l'évidence de la passion».

\section{EL ENCUENTRO}

El punto de llegada de ese escrito autobiográfico (no memorias) que es Résidente privilégiée es el encuentro de una nueva identidad: "Mon nom est Maria Casarès. Je suis née en novembre 1942 au théâtre des Mathurins» 
(Casares, 1980: 344); el teatro supone para María un segundo nacimiento y se convierte en una segunda patria; en esta segunda patria «ma nationalité -comme mes origines- reste espagnole ou, pour mieux dire, refugiée espagnole en France.» (Ibid.: 354). Sin embargo, más adelante, esa segunda patria la lleva hasta André, el hombre que le da su apellido, como antes su padre, con lo que adquiere la nacionalidad francesa (Ibid.: 432). Dos tarjetas de identidad reflejan estas dos etapas: la Carte de séjour de Résidente privilégiée (Ibid:: 352-353), que es la que da título al libro, y la Carte d'identité (Ibid:: 420); la primera es sólo un carnet temporal, un «document délivré par les autorités administratives aux étrangers dont le séjour dépasse une durée de trois mois», en el que consta, asimismo, la condición privilegiada de María como hija de un dirigente republicano exiliado que es; la segunda es un carnet de identidad que la convierte en ciudadana francesa con plenos derechos. Con todo y ser importante esta segunda identidad, la primera se impone; ya no es una cuestión de países ni de lenguas sino de teatro: «No se puede decir categórica y excluyentemente: soy espańola, soy francesa. En realidad, desde 1942, mi patria es el teatro, que es universal.» (Casares, julio de 1991: 310). 


\section{BibliografíA CITADA}

Aznar Soler Manuel, «Materiales para la memoria de un mito: María Casares y el exilio republicano español de 1939», en Escritores, editoriales y revistas del exilio republicano de 1939, ed. de Manuel Aznar Soler, Sevilla, GEXEL, Renacimiento, 2006, pp. 1073-1107.

Bajtin Mijail, Teoría y estética de la novela. Trabajos de investigación (1978), Madrid, Taurus, 1989.

Barthes Roland, «La tragédienne sans public», France-Observateur, 27 de mayo de 1954, Euvres complètes. Tome I. 1942-1961, Paris, Éditions du Seuil, 2002, pp. 493-496.

Brunel Pierre, «Un mythe de la croissance» en Le mythe de la métamorphose, Paris, Armand Colin, 1974, pp. 94-123.

Caballé Anna, "Memorias y autobiografías escritas por mujeres (siglos XIX y XX)», en Breve historia feminista de la literatura española (en lengua castellana). V. La literatura escrita por mujer (del siglo XIX a la actualidad), ed. de Iris M. Zavala, Barcelona, Anthropos, 1998, pp. 111-137.

Caro Baroja Julio, Las brujas y su mundo, tercera ed., Madrid, Alianza, 1969.

Carpentier Alejo, "Un libro de memorias. María Casares, Residente privilegiada», La Vanguardia, 29 de marzo de 1980, p. 5.

Casares María, Résidente privilégiée, Paris, Fayard, 1980.

- A fondo (entrevista de Joaquín Soler Serrano emitida el 26 de abril de 1981), TVE, 1981a, 58 minutos.

- Residente privilegiada, Barcelona, Argos Vergara, 1981b.

- Entrevista (julio de 1991), en Carlos Fernández Santander, Casares Quiroga, una pasión republicana, Sada, Ediciós do Castro, 2000, pp. 307-312.

- Residente privilexiada, A Coruña, Editorial Trifolium, 2009.

Cerda Gutiérrez Hugo, Ideología y cuentos de hadas, Madrid, Akal, 1985.

Delgado María M. "A Spanish actress on the French stage: María Casares», "Other" Spanish Theatres. Erasure and Inscription on the Twentieh-Century Spanish Stage, Manchester University Press, 2003, pp. 90-131.

Dijkstra Bram, Ídolos de perversidad. La imagen de la mujer en la cultura de fin de siglo, Madrid/Barcelona, Editorial Debate/Círculo de Lectores, 1994.

Dussane Béatrix Maria Casares, Paris, Calmann-Lévy, 1953.

Eliade Mircea, Lo sagrado y lo profano (1957), segunda ed., Barcelona, Labor, 1994.

- Iniciaciones misticas (1958), Madrid, Taurus, 1984.

- Mito y realidad (1963), segunda edición, Madrid Guadarrama, 1973.

Figuero Javier y Marie-Hélène Carbonel, Maria Casarès l'étrangère, Paris, Fayard, 2005.

Gouhier Henry, La esencia del teatro. Con testimonios de Georges Pitoeff, Charles 
Dullin, Louis Jouvet, Gaston Baty, Buenos Aires, Ediciones del Carro de Tespis, 1956.

Grillo Rosa María, «María Casares, residente privilegiada en París», en Literatura y cultura del exilio español de 1939 en Francia, ed. de Alicia Alted Vigil y Manuel Aznar Soler, Salamanca, AEMIC-GEXEL, 1998, pp. 119-127.

Lopo María, «María Casares. A Galicia cosmopolita», Unión Libre. Cadernos de vida e culturas, no 11, 2006, pp. 153-174.

- Cartas no exilio. Correspondencia entre Santiago Casares Quiroga e María Casares (1946-1949), A Coruña, Baía Edicións, 2008.

Meletinski Eleazar M., El mito. Literatura y folklore, Madrid, Akal, 2001.

Monleón José, «Vísperas de El adefesio. París. Con Rafael y María», Tiempo y teatro de Rafael Alberti, Primer Acto, 1990, pp. 413-445.

Nietzsche Friedrich, El nacimiento de la tragedia (1871), cuarta ed., Madrid, Alianza, 1979.

Ortega Francisco, «En la muerte de María Casares», Primer acto, no 267, enerofebrero de 1997, pp. 106-116.

Ortega y Gasset José, Idea del teatro (1946), Madrid, Revista de Occidente, 1958.

Rivas Manuel, «María Casares, a muller rebelde», Casa Hamlet, no 3, 2001, pp. 1419.

Romero López Dolores, "Las actrices», en Teatro y memoria en la segunda mitad del siglo XX. Actas del XII Seminario Internacional del Centro de Investigación de Semiótica literaria, teatral y nuevas tecnologias. Madrid, UNED, 26-28 de junio de 2003, Visor libros/UNED, 2003, pp. 285-312.

Ruiz Mata José, «De ritos de iniciación: La princesa y la rana, El patito feo, La Bella y la Bestia", Del color del cisne. Una reflexión sobre los cuentos, Jerez de la Frontera, Asociación Cultural Barataria, 2003 pp. 110-117.

Soriano Jacinto, «María Casares: Teatro en carne viva», El Público, 58-59, julioagosto de 1988, pp. 60-62.

Warner Marina, Fantastic Metamorphoses, Other Worlds. Ways of Telling the Self, Oxford, Oxford University Press, 2002.

Zumalde Imanol, "Directo á medula (La chartreuse de Parme, 1948)», en AA.VV., Entre o exilio e o reino. María Casares, unha actriz fronte á cámara, ed. de José Luis Castro de Paz, Jaime J. Pena Pérez e outros, Orense, Servicio Galego de Igualdade, 2002, pp. 93-104. 